\title{
Investigations on a diesel engine fuelled with biodiesel blends and diethyl ether as an additive M. Pugazhvadivu ${ }^{1}$ and S. Rajagopan ${ }^{2}$
${ }^{1}$ Dept. of Mechanical Engineering, ${ }^{2}$ Dept. of Chemistry, Pondicherry Engineering College, Puducherry, India-605 014 pv_pec@yahoo.com

Abstract: A single cylinder direct injection diesel engine was fuelled with blends of biodiesel and diesel at different proportions. The engine performance and emission characteristics were determined. The engine $\mathrm{NO}_{x}$ emission was noted to be higher than the diesel fuel operation with all blends. Diethyl ether was then added at different proportions to the blends. The addition of diethyl ether to the blends reduced the $\mathrm{NO}_{x}$ emission at low and medium loads; however, at high loads the $\mathrm{NO}_{x}$ emission was higher compared to diesel and lower compared to the corresponding biodiesel blend. The addition of diethyl ether to biodiesel blends reduced the both $\mathrm{NO}_{\mathrm{x}}$ and smoke emission further.

Keywords: Biodiesel, diethyl ether, $\mathrm{NO}_{\mathrm{x}}$, Pongamia oil. Introduction

The steady increase in energy consumption coupled with environmental pollution has promoted research activities in alternative and renewable energy fuels. Many countries in the world are continuously developing materials and methods for effectively utilising the alternative fuel resources available in their region. Among the various alternative fuels, biodiesel has received significant attention in recent years due to its environmental benefits. Studies have been carried out to find new biological resources for biodiesel production, and to utilise it as a fuel to run diesel engines.

Biodiesel is non-toxic and biodegradable. The combustion of biodiesel contributes less $\mathrm{CO}_{2}$ to the atmosphere as it is captured by the growing plants for photosynthesis. Studies on using biodiesel as fuel in diesel engines have shown greater reduction in emissions of hydrocarbons, smoke, particulate matter, oxides of sulphur and carbon and polyaromatics as compared to diesel (Graboski \& McCormick, 1997, Wang et al., 2000, Agarwal \& Das, 2001, Kalligeros et al., 2003, Ramadass et al., 2005; Hanumantha Rao et al., 2009; Hariharan et al., 2009). However, the studies on direct injection diesel engines have shown an increase in oxides of nitrogen $\left(\mathrm{NO}_{\mathrm{x}}\right.$ ) (Serdari et al., 2000; Shi et al., 2005, Nabi et al., 2006). The NOx emissions are known to contribute to the formation of ground level ozone and fine particles that impair visibility.

Retarding fuel injection timing can reduce $\mathrm{NO}_{x}$ with a loss of some effectiveness for particulate matter reduction and a loss of fuel economy. The other approach to reduce $\mathrm{NO}_{\mathrm{x}}$ emissions to a level equal to that from conventional diesel engine is to increase the cetane number of the fuel. Chemicals such as alkyl nitrates and certain peroxides can serve as cetane improvers. Serdari et al. (2000) used isoResearch article CIndian Society for Education and Environment (iSee) octyl nitrate and a combustion improver for reducing the $\mathrm{NO}_{x}$ emissions from a single cylinder diesel engine fuelled with biodiesel. Szybist et al. (2005) used 2-ethyl hexyl nitrate as fuel additive in B20 blend to combat the NOx emission.

In the present work, the effect of adding diethyl ether (DEE) to biodiesel blends was studied. DEE can be produced by dehydration of bio-ethanol, a renewable fuel. DEE has long been recommended as a cold starting additive in diesel engines and gasoline engines due to its low autoignition temperature and high volatility (Gupta, 1988). The properties of DEE permit it to be used as a fuel for compression ignition engines; either as a neat fuel or as a blend with diesel. The auto ignition temperature of DEE is lower than diesel. DEE has a high cetane number of greater than 125 . Its heating value is comparable to that of diesel. The latent heat of vaporization is higher than diesel. DEE is a liquid at room temperature which reduces handling and storage problems. DEE is also non-corrosive compared to alcohols. The properties which need concern are its high flammability and poor storage stability. DEE also poses human health problems due to its anaesthetic effect.

DEE as a fuel additive has shown to offer beneficial effects in terms of both performance and emissions. Anand \& Mahalakshmi (2007) have showed that a $20 \%$ DEE in diesel along with 5\% EGR result in the simultaneous reduction of smoke and $\mathrm{NO}_{x}$ emission. Recently, Ramadhas et al., (2008) studied the use of DEE as a fuel additive for reducing the cold starting problem and to improve the performance and emission characteristics of a diesel engine fuelled with biodiesel.

In this work, pongamia oil derived from the seeds of Pongamia pinnata is used to produce biodiesel. $P$. pinnata has been recognized as one of the most suitable among other plant species such as Jatropha curcus and Madhuca indica for producing biodiesel. The tree is tolerant to water logging, saline and alkaline soils; it can withstand harsh climates and planted on degraded boundaries of farmer's land or wastelands. It is one of the few nitrogen-fixing trees producing seeds containing 30$40 \%$ oil (Barnwal \& Sharma, 2005).

In this work, the effect of adding DEE to biodieseldiesel blends (B25, B50 and B75) and biodiesel (B100) were investigated. DEE was added in $10 \%, 15 \%$ and $20 \%$ $(\mathrm{v} / \mathrm{v})$ to the biodiesel fuels.

Materials and methods

The engine performance and emission studies were conducted on a Kirloskar make, single cylinder, direct injection diesel engine. The engine specifications are presented in Pugazhvadivu \& Rajagopan Indian J.Sci.Technol. 
Table 1. The engine was coupled to an electrical dynamometer and a resistance load bank to operate it under various loads. Two separate tanks of 5 liter capacity were used for storing diesel and biodieselblends with diesel. A fuel switching valve arrangement was provided to change over from one fuel to another while the engine was running. The fuel was fed to the injector pump under gravity and the volumetric fuel flow rate was measured by using a burette and stop watch. The exhaust gas temperature was measured using thermocouple connected to a temperature indicator. The exhaust emissions were measured by a smoke meter and $\mathrm{NO}_{\mathrm{X}}$ analyzer.

The unrefined pongamia oil has a free fatty acid (FFA) content of $15 \%$. A two step process was used to convert the high FFA oil into biodiesel (Canakci \& Van Gerpen, 2001, Ghadge \& Raheman, 2005, Ramadhas et al., 2005). In the first step, $1 \%(\mathrm{v} / \mathrm{v})$ sulfuric acid, an acid catalyst was used to esterify the FFA to methyl esters, thereby reducing the FFA level. In the second step, the low-FFA oil was transesterified with $0.6 \%$ (w/w) potassium hydroxide, an alkali catalyst to convert the triglycerides to biodiesel. The reactions were carried out in a 5 liter batch reactor for 1 hour at a temperature of $60^{\circ} \mathrm{C}$.

The engine experiments were conducted with diesel fuel, biodiesel- diesel blends containing $25 \%, 50 \%, 75 \%$ (v/v) biodiesel (B25, B50 and B75 respectively) and biodiesel (B100). DEE was added to all the biodiesel fuels in proportions of $10 \%$, $15 \%$ and $20 \%(\mathrm{v} / \mathrm{v})$ and the impact on engine performance and emissions were measured. The fuel Research article CIndian Society for Education and Environment (iSee)
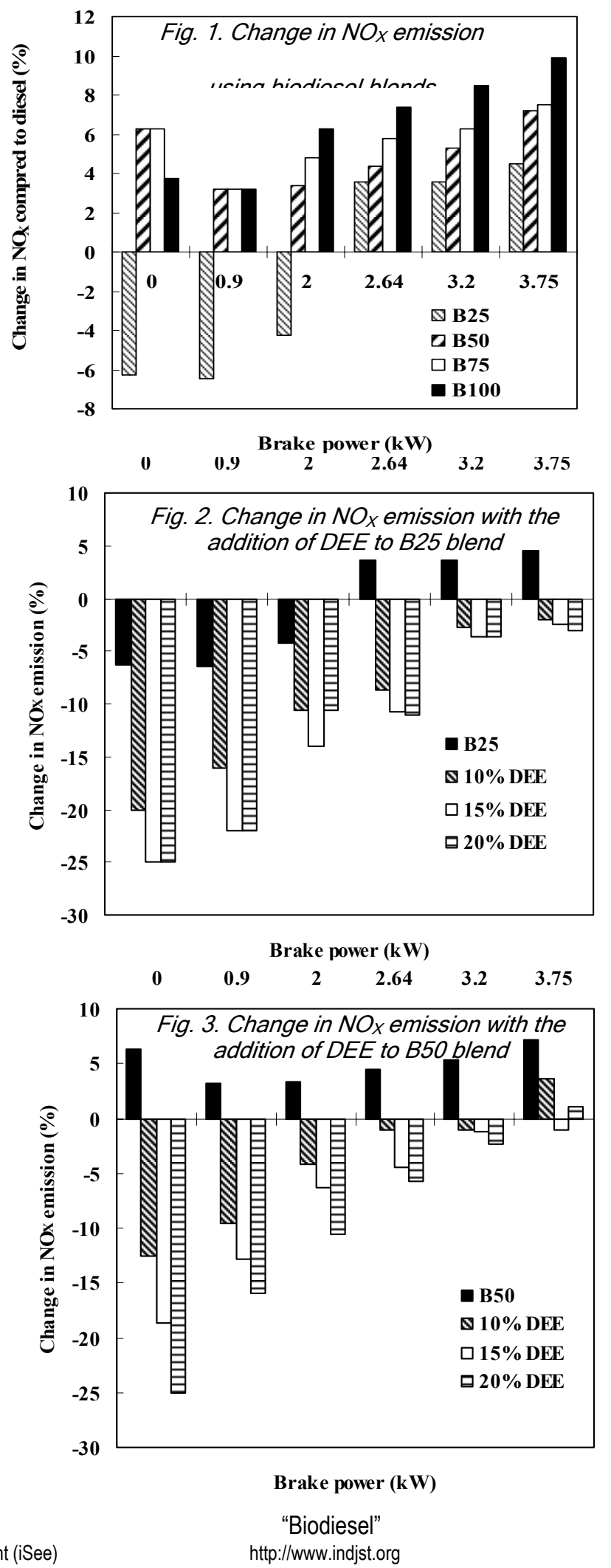

ISSN: 0974- 6846

consumption and emission measurements (NOx and smoke) were taken under various loads and at constant speed.

Results and discussion

The $\mathrm{NO}_{x}$ emission from the engine using $\mathrm{B} 25, \mathrm{~B} 50$, $\mathrm{B} 75$ and B100 as fuels were measured and compared with that of diesel. The percentage change in $\mathrm{NO}_{x}$ was calculated and presented in Fig. 1 . It is seen that with increase in the concentration of biodiesel in the blend, there is an increase in $\mathrm{NO}_{x}$ emission. The $\mathrm{NO}_{x}$ formation depends on the availability of oxygen and combustion temperature (Heywood, 1988). The oxygen in biodiesel oxidizes nitrogen, thereby increasing $\mathrm{NO}_{x}$ emissions (Serdari et al., 2000). It is seen from the results, B25 a blend containing the lowest concentration of biodiesel produces lower $\mathrm{NO}_{x}$ emissions compared to all other biodiesel blends due to its lesser oxygen content.

The impact of adding DEE to biodiesel fuels on $\mathrm{NO}_{X}$ emission is presented in Fig. 2 to Fig.5. The results indicates that, in general, the addition of diethyl ether to B25, B50, B75 and B100 decrease $\mathrm{NO}_{x}$ emission compared to diesel fuel operation. This result is expected as DEE is a cetane improver and any increase in cetane number decreases $\mathrm{NO}_{x}$ emission (Serdari et al., 2000). Another reason may be the high latent heat of evaporation of DEE compared to either diesel (Huang et al., 1999) which is beneficial to the $\mathrm{NO}_{x}$ reduction owing to the larger temperature drop of the mixture in the cylinder. The results also indicate that at high loads, there is no significant reduction in $\mathrm{NOx}$ emission with DEE addition to B25 blend. Also, at the same operating condition the $\mathrm{NO}_{x}$ emission using B50, B75 and B100 were higher compared to diesel fuel operation. This result Indian J.Sci.Technol 
was reasonable, since at high loads the combustion emission was lowered by the addition of DEE at low and temperature becomes high which play a dominant role in the formation of $\mathrm{NO}_{x}$. DEE added in proportions of $15 \%$ and $20 \%$ were found to give better reduction in $\mathrm{NO}_{\mathrm{x}}$ compared to $10 \%$ DEE addition.

The results of smoke emission measurements are presented in Fig. 6. It is seen that, the smoke emission was reduced using biodiesel blends. The availability of oxygen in the biodiesel blends leads to better combustion and reduced the smoke emission. The smoke emission decreased by $2 \%, 16 \%, 23 \%$ and $26 \%$ using B25, B50, B75 and $\mathrm{B} 100$ blends respectively compared to diesel at full load.

The effect of adding DEE to biodiesel blends on smoke emission is presented in Fig. 7 to Fig.10. It is seen that the smoke emission reduced significantly by the addition of DEE to biodiesel blends. This may be due to the presence of oxygen in DEE. The addition of $15 \%$ and $20 \%$ DEE to biodiesel fuels was found to give significant reduction in smoke emission. The addition of $20 \%$ DEE to B25, B50, B75 and B100 blends reduced smoke emission by $13 \%, 23 \%, 34 \%$ and $36 \%$ respectively compared to diesel.

The results of engine thermal efficiency using different biodiesel blends are given in Fig. 11. With all the biodiesel blends, the thermal
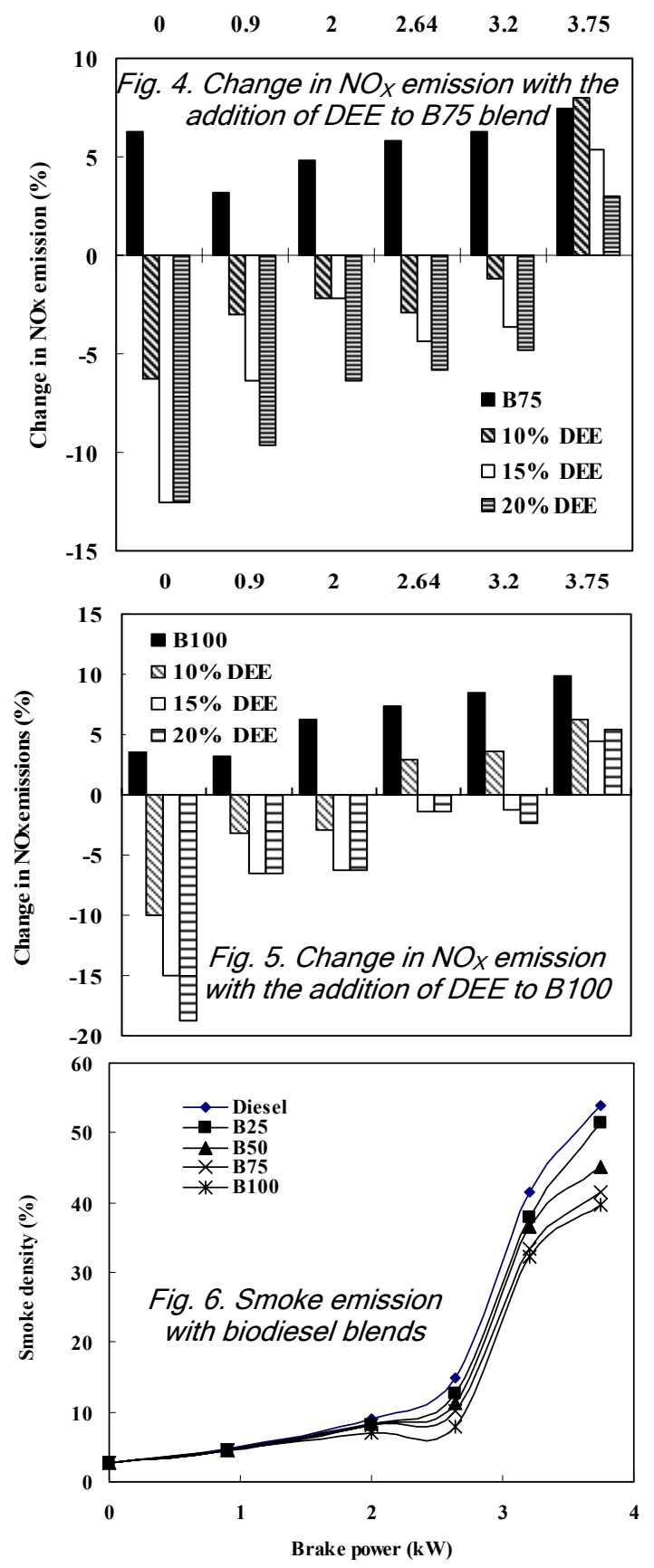
medium loads. However, at high loads the $\mathrm{NO}_{\mathrm{x}}$ emission was higher relative to diesel; but lower compared to the corresponding fuel blend. The addition of $15 \%$ to $20 \%$ DEE was more beneficial in reducing $\mathrm{NO}_{\mathrm{X}}$ compared to $10 \%$ DEE

The biodiesel blends tested showed a significant reduction in smoke emission. Further improvement in smoke emission was obtained by the addition of DEE. The addition of DEE resulted in a marginal deterioration of thermal efficiency. It is concluded that the addition of $15 \%-20 \%$ DEE to biodiesel blends would result in reduction of both $\mathrm{NO}_{x}$ and smoke emission.

Acknowledgement

The authors acknowledge the financial support provided by the Department of Science and Technology, Government of India.

\section{References}

1. Agarwal AK and Das LM (2001)

Biodiesel development and characterization for use as a fuel in compression ignition engine. J. Engg. Gas. Turb. \& Pow. 123, 440-447.

2. Anand $R$ and Mahalakshmi NV (2007) Simultaneous reduction of $\mathrm{NO}_{\mathrm{x}}$ and smoke from a directinjection diesel engine with exhaust gas recirculation and diethyl ether. Proc. IMechE. J. Auto. Engg. 221, 109-16.

3. Barnwal BK and Sharma MP (2005) Prospects of biodiesel production from vegetable oils in India. J. Renew. \& Sust. Energ. Rev. 9, 363-378.

4. Canakci M and Van Gerpen JH efficiency decreased marginally compared to diesel due to the lower heating value of biodiesel. Fig. 12 shows the effect of adding $20 \%$ DEE to biodiesel blends. The results indicate that the addition of DEE decrease the thermal efficiency maginally due to the lower heating value of DEE.

Conclusion

All the biodiesel blends produced a higher $\mathrm{NO}_{\mathrm{x}}$ emission compared to diesel. With B25 blend, the $\mathrm{NO}_{\mathrm{x}}$ emission was reduced by the addition of DEE at all load conditions. With B50, B75 and B100 blends, the $\mathrm{NO}_{\mathrm{X}}$ high free fatty acids. Trans. Am. Soc. Agri. Engrs. 44, 1429-1436.

5. Ghadge SV and Raheman H (2005) Biodiesel production from mahua (madhuca indica) oil having high free fatty acids. Biomas.\& Bioenerg. 28(6), 601605.

6. Graboski MS and McCormick RL (1997) Combustion of fat and vegetable oil derived fuels in diesel engines. Prog. Energ. \& Combn. Sci. 24, 125-164. 

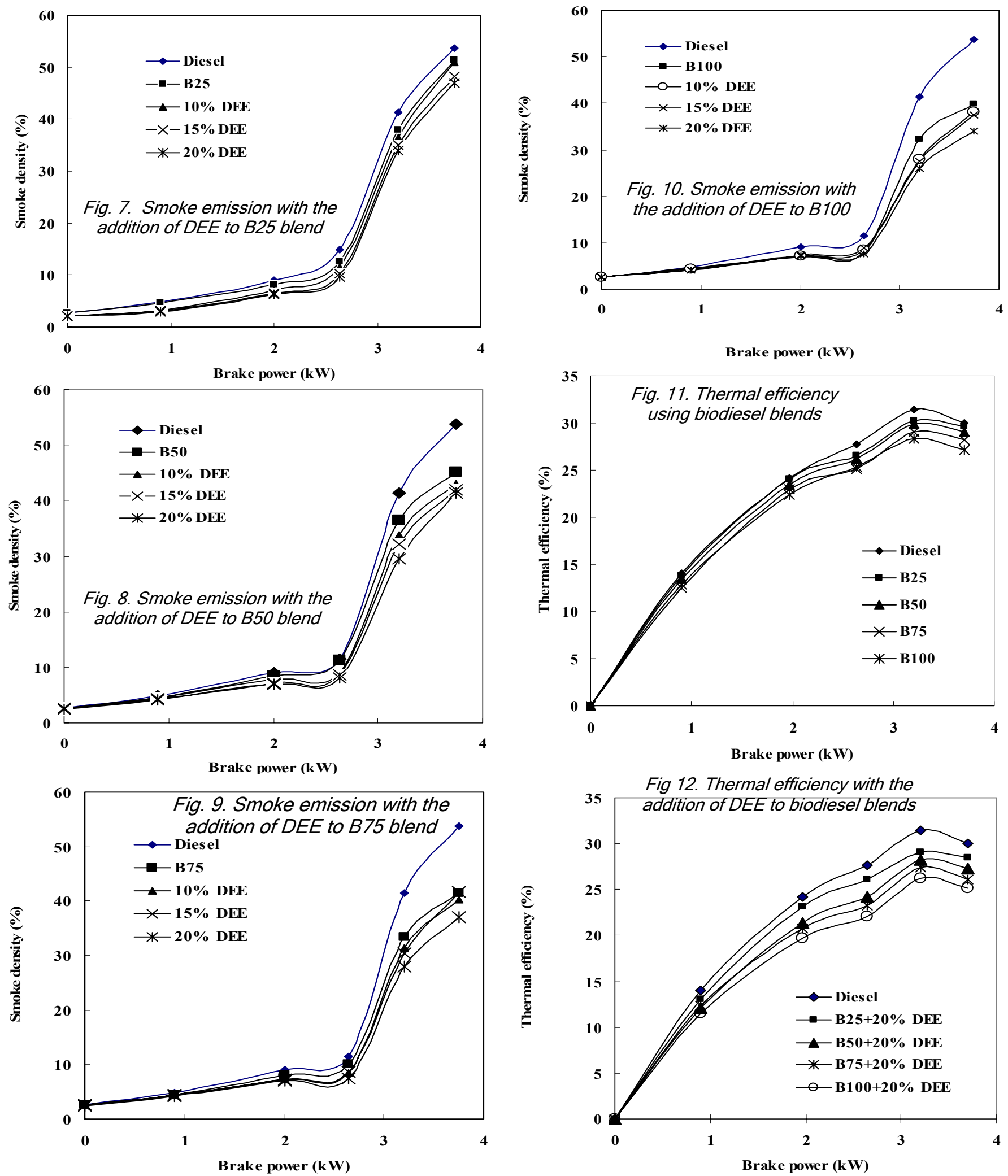

Research article

CIndian Society for Education and Environment (iSee)
"Biodiesel" http://www.indjst.org
Pugazhvadivu \& Rajagopan Indian J.Sci.Technol. 
7. Gupta RB (1988) Cold Starting of IC Engines. Def. Sci.J. 38 (1), 77-85.

8. Hanumantha Rao YV, Ram Sudheer Voleti, Sitarama Raju AV and Nageswara Reddy P (2009) Experimental investigations on jatropha biodiesel and additive in diesel engine. Indian J. Sci. Technol. 2 (4) 25-31. Domain site: http://www.indjst.org.

9. Hariharan VS, Vijayakumar Reddy K and Rajagopal K (2009) Study of the performance, emission and combustion characteristics of a diesel engine using Sea lemon oilbased fule. Indian J. Sci. Technol. 2 (4) 43-47. Domain site: http://www.indjst.org.

10. Heywood JB (1988) Internal Combustion Engines Fundamentals, McGraw Hill, NY.

11. Huang ZH, Wang HW, Chen HY, Zhou LB and Jiang DM (1999) Study of combustion characteristics of a compression ignition engine fuelled with dimethyl ether. Proc. IMechE. J. Auto. Engg. 213, 647-652.

12. Kalligeros $S$, Zannikos $F$, Stournas $S$, Lois $E$, Anastopoulos G, Teas $\mathrm{CH}$ and Sakellaropoulos $\mathrm{F}$ (2003) An investigation of using biodiesel/marine diesel blends on the performance of a stationary diesel engine. Biomas. \& Bioenerg. 24, 141-149.

13. Nabi MN, Akhter MS and Shahadat MMZ (2006) Improvement of engine emissions with conventional diesel fuel and diesel-biodiesel blends. Biores. Tech. 97, 372-378.

14. Ramadass AS, Muraledaran C and Jayaraj S (2005) Performance and emission evaluation of a diesel engine fuelled with methyl esters of rubber seed oil. Renew. Energ. 30, 1789-1800.

15. Ramadhas AS, Jayaraj, S and Muraleedharan C (2005). Biodiesel production from high 'FFA' rubber seed oil. Fuel. 84(4), 335-340.

16. Serdari A, Fragioudakis K, Kalligeros $S$, Stournas $S$, and Lois E (2000) Impact of using biodiesel of different origin and additives on the performance of a stationary diesel engine. J. Engg. Gas Turb. \& Pow. 122, 624-631.

17. Shi X, Yu Y, He H, Shuai S, Wang J and Li R (2005) Emission characteristics using methylsoyate-ethanoldiesel fuel blends on a diesel engine. Fuel. 84, 15431549.

18. Szybist JP, Boehman AL, Taylor JD and McCormick $\mathrm{RL}$ (2005) Evaluation of formulation strategies to eliminate the biodiesel $\mathrm{NO}_{\mathrm{x}}$ effect. Fuel Process. Tech. 86, 1109- 1126.

19. Wang WG, Lyons DW, Clark NN, Gautham M and Nortan PM (2000) Emissions from nine heavy duty trucks fuelled by diesel and biodiesel blend without engine modification. Envi. Sci. \& Tech. 34, 2000, 933939. 